Article

\title{
Combination of Lactobacillus plantarum and Saccharomyces cerevisiae DV10 as Starter Culture to Produce Mango Slurry: Microbiological, Chemical Parameters and Antioxidant Activity
}

\author{
Xiaofan Jin ${ }^{1}$, Wenxue Chen ${ }^{1}$, Haiming Chen ${ }^{1}{ }^{(}$, Weijun Chen ${ }^{1,2, *}$ and Qiuping Zhong ${ }^{1, *}$ \\ 1 College of Food Science and Engineering, Hainan University, Haikou 570228, China; \\ jinxiaofan412@163.com (X.J.); hnchwx@163.com (W.C.); hmchen168@126.com (H.C.) \\ 2 Chunguang Agro-Product Processing Institute, Wenchang 571333, China \\ * Correspondence: chenwj@nwu.edu.cn (W.C.); hainufood88@163.com (Q.Z.); \\ Tel./Fax: +86-89866193851 (W.C. \& Q.Z.)
}

Academic Editor: Daniel Cozzolino

Received: 14 October 2019; Accepted: 26 November 2019; Published: 28 November 2019

\begin{abstract}
The aim of this study was to develop a nondairy fermented product based on mango slurry. Lactobacillus plantarum and Saccharomyces cerevisiae DV10 were used as starter cultures in single and co-cultivations. The microbial populations and metabolites produced during mango slurry fermentation were investigated. At the end of all fermentations, the bacterial populations were higher than $6.0 \log \mathrm{CFU} / \mathrm{mL}$. Lactic acid was the main organic acid produced, achieving up to $6.12 \mathrm{~g} / \mathrm{L}$ after $24 \mathrm{~h}$ in co-culture with L. plantarum and S. cerevisiae DV10. Volatile compounds were determined after $24 \mathrm{~h}$ of fermentation, the co-cultures of L. plantarum and S. cerevisiae DV10 could decrease terpenes and produce alcohols and esters. The co-cultivations obtained the most total phenolics as well as showed the strongest 2,2' -azinobis-(3-ethylbenzothiazoline-6-sulfonate) (ABTS) radical scavenging activity, ferric-reducing antioxidant power (FRAP) and low-density lipoprotein (LDL) oxidation inhibition. Hence, a high-bioactivity probiotic product was successfully obtained via mango slurry fermentation inoculated with a co-culture of L. plantarum and S. cerevisiae DV10.
\end{abstract}

Keywords: probiotic product; mango slurry; Lactobacillus plantarum; Saccharomyces cerevisiae; volatile compounds; antioxidant power

\section{Introduction}

Probiotics microorganisms benefit the health of the host by improving the intestinal microbiota composition [1]. At present, there is growing interest in the development of new functional foods and the use of probiotic microorganisms in healthy diets [2]. Using probiotic microorganisms to ferment beverages can improve the nutritional value and sensory properties of these beverages [3]. The use of probiotic microorganisms in dairy beverages has been widely promoted [2]. However, high fat, high cholesterol, lactose intolerance, milk allergy and vegetarian growth have prompted study in the field of nondairy probiotic products [2]. Fruit are rich in nutrients and contain sugars to support the growth of probiotic microorganisms. Therefore, fruit are considered to be an ideal substrate for the development of nondairy probiotic beverages [4].

Mangoes (Mangifera indica L.) are rich in nutrients, sweet and delicious and are popular among the public. It is among the most important tropical fruit in the world [5]. The production and international trade of mangoes are gradually expanding [6]. Mangoes contain a variety of biologically active compounds, such as polyphenols, carotenoids, vitamins and dietary fiber, and have nutritional and 
antioxidant properties [7]. Due to its juicy and sweet taste, mangoes are known as the king of fruit and are widely used by consumers throughout the world at various maturity stages. Besides the fresh fruit, mangoes are processed into various products such as slices, juices, nectars and jams [8]. As far as we know, a study of a mixed fermentation mango slurry using lactic acid bacteria (LAB) and yeast has not been reported. Mixed culture fermentations provide complex growth patterns that can also considerably affect the functional and organoleptic properties of food [9]. Hence, the aim of this work was to develop a novel mango slurry product fermented by using probiotic strain Lactobacillus plantarum association with yeast Saccharomyces cerevisiae DV10. Microbial growth during fermentation, $\mathrm{pH}$ and the contents of organic acids, volatile compounds and total phenols before and after fermentation were determined. Furthermore, antioxidant capacity and copper-induced low-density lipoprotein (LDL) oxidation were also evaluated.

\section{Results and Discussion}

\subsection{Microbial Growth Performance During Mango Slurry Fermentation}

Figure 1 shows the microbial growth of S. cerevisiae DV10 and L. plantarum during single and co-culture fermentations of mango pulp. The growth rate of L. plantarum was not affected by the presence of S. cerevisiae DV10 in the mixed culture and remained similar to that of the L. plantarum pure culture (Figure 1A). Other studies have used a combination of LAB and yeast to ferment oats; the observed behavior of LAB was similar to our results [10]. There was no significant $(p>0.05)$ difference in the bacterial population in the single or co-culture assays $(9.07 \log \mathrm{CFU} / \mathrm{mL}$ and $9.11 \mathrm{log}$ $\mathrm{CFU} / \mathrm{mL}$, respectively) at $24 \mathrm{~h}$ of fermentation, and the bacterial populations of both approaches were significantly $(p<0.05)$ higher than the initial population $(7.16 \log \mathrm{CFU} / \mathrm{mL})$. High viable counts were important to get the lower $\mathrm{pH}$, growth of contaminants was prevented [11].

a

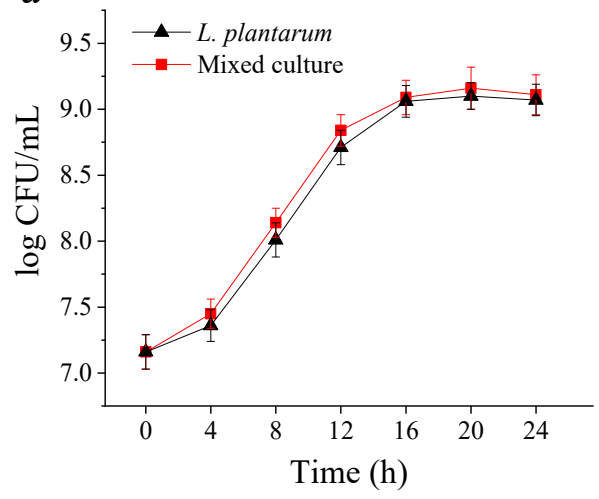

$\mathrm{b}$

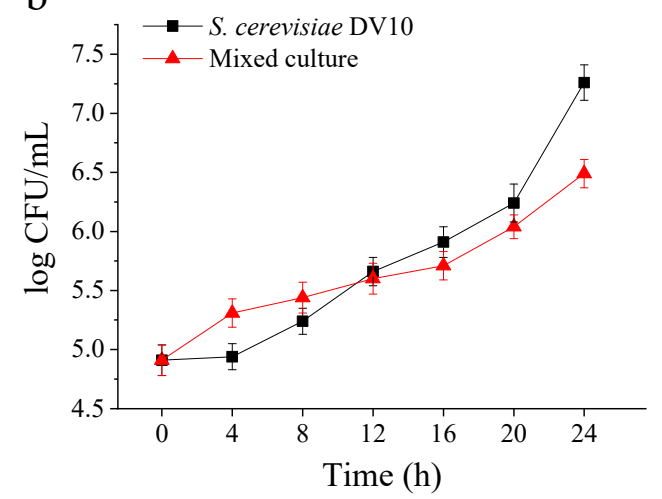

Figure 1. Microbial populations during single and co-culture fermentations of mango slurry. (a) Populations of Lactobacillus plantarum in single and mixed culture fermentations. (b) Populations of Sacharomyces cerevisiae DV10 in single and mixed culture fermentations.

Regarding S. cerevisiae DV10, as shown in Figure 1B, the initial population was $4.91 \log$ CFU/mL. The population in single and co-culture fermentations significantly increased $(p<0.05)$ within $24 \mathrm{~h}$, reaching $7.26 \log \mathrm{CFU} / \mathrm{mL}$ and $6.49 \log \mathrm{CFU} / \mathrm{mL}$. The populations obtained at $24 \mathrm{~h}$ of fermentation were higher than that required for probiotic products $(6-7 \log \mathrm{CFU} / \mathrm{mL})$ to have a healthy effect on the gastrointestinal tract when consumed [10]. After $24 \mathrm{~h}$ of fermentation, the population of S. cerevisiae DV10 in single culture was higher than that of the mixed culture. This may be due to the inhibition of S. cerevisiae DV10 by cyclic peptides and phenyl lactic acid produced by L. plantarum growth and metabolism. Co-cultured organisms may compete for nutrients or may produce metabolites that stimulate or inhibit each other's growth [9]. The results show that the combination of L. plantarum and S. cerevisiae DV10 can be appropriate for fermenting mango pulp. 


\subsection{Quality Parameters}

The $\mathrm{pH}$ of mango pulp fermented with L. plantarum (single and co-culture) rapidly decreased from 4.12 to 3.55 over $24 \mathrm{~h}$ (Table 1). The $\mathrm{pH}$ of the single S. cerevisiae DV10 fermented mango pulp was observed to decrease from 4.12 to 3.98 . This may have been related to the higher amount of lactic acid in the fermentation of L. plantarum. After $24 \mathrm{~h}$ of fermentation, the total soluble solids (TSS) of S. cerevisiae DV10 (single and co-culture) fermented mango pulp decreased from 21.6 to $20.2^{\circ}$ Brix, and the reducing sugar content decreased from 2.24 to $1.97 \mathrm{~g} / \mathrm{L}$. TSS in the mango pulp fermented with single L. plantarum decreased from 21.6 to $21.2^{\circ}$ Brix, and the reducing sugar content decreased from 2.24 to $2.13 \mathrm{~g} / \mathrm{L}$. After $24 \mathrm{~h}$ of fermentation, the $S$. cerevisiae DV10 (single and co-culture) cultures were significantly lower $(p<0.05)$ in TSS and reducing sugar content than the single L. plantarum culture (Table 1).

Table 1. Quality parameters, total phenolic content (TPC) and antioxidant capacity of mango slurry before and after $24 \mathrm{~h}$ fermentation.

\begin{tabular}{ccccccc}
\hline Samples & pH & TSS $\left(^{\circ}\right.$ Brix) & $\begin{array}{c}\text { Reducing } \\
\text { Sugars }(\mathbf{g} / \mathbf{L})\end{array}$ & $\begin{array}{c}\text { TPC } \\
(\mathbf{m g} \text { GAE/100 mL) }\end{array}$ & $\begin{array}{c}\text { ABTS } \\
(\% \mathbf{~ I n h})\end{array}$ & $\left.\begin{array}{c}\text { FRAP } \\
(\mathbf{m M} \text { FeSO }\end{array}\right)$ \\
\hline Unfermented & $4.12 \pm 0.15 \mathrm{~b}$ & $21.6 \pm 0.5 \mathrm{~b}$ & $2.24 \pm 0.07 \mathrm{~b}$ & $75.87 \pm 1.43 \mathrm{a}$ & $10.43 \pm 0.25 \mathrm{a}$ & $1.11 \pm 0.03 \mathrm{a}$ \\
L. plantarum & $3.54 \pm 0.09 \mathrm{a}$ & $21.2 \pm 0.4 \mathrm{~b}$ & $2.13 \pm 0.06 \mathrm{~b}$ & $86.59 \pm 1.29 \mathrm{c}$ & $15.29 \pm 0.31 \mathrm{c}$ & $1.47 \pm 0.04 \mathrm{~b}$ \\
S. cerevisiae DV10 & $3.98 \pm 0.12 \mathrm{~b}$ & $20.2 \pm 0.5 \mathrm{a}$ & $1.97 \pm 0.04 \mathrm{a}$ & $79.41 \pm 1.65 \mathrm{~b}$ & $12.72 \pm 0.29 \mathrm{~b}$ & $1.16 \pm 0.02 \mathrm{a}$ \\
Co-culture & $3.55 \pm 0.07 \mathrm{a}$ & $20.3 \pm 0.4 \mathrm{a}$ & $2.00 \pm 0.05 \mathrm{a}$ & $89.25 \pm 1.06 \mathrm{~d}$ & $16.11 \pm 0.34 \mathrm{~d}$ & $1.49 \pm 0.05 \mathrm{~b}$ \\
\hline
\end{tabular}

Data represent the mean $\pm \mathrm{SD}$; values with different letters $(\mathrm{a}-\mathrm{d})$ in the same column are significantly different at $p<0.05$; TSS, total soluble solids; TPC, total phenolic content; Inh, inhibition.

\subsection{Changes in TPC, ABTS and FRAP}

Total phenolic content (TPC) in the unfermented mango pulp were $75.87 \mathrm{mg}$ GAE/100 mL (Table 1). TPC of the single S. cerevisiae DV10, single L. plantarum and mixed fermentation mango pulp were $79.41,86.59$ and $89.25 \mathrm{GAE} / 100 \mathrm{~mL}$ at $24 \mathrm{~h}$ of fermentation, respectively. Long-term consumption of plant polyphenol-rich diets can prevent the development of cancer, cardiovascular disease and diabetes [12]. In addition, the lower $\mathrm{pH}$ of the L. plantarum fermented juice was beneficial to the stability of polyphenols because they were auto-oxidized as the $\mathrm{pH}$ increases [13]. Some studies have found that fermenting juice with $\mathrm{LAB}$ can alleviate the degradation of macropolymeric phenolic substances and increase the total phenolics $[14,15]$. TPC in the co-cultivation of S. cerevisiae DV10 and L. plantarum was the highest over $24 \mathrm{~h}$.

After $24 \mathrm{~h}$ of fermentation, the ABTS free radical scavenging ability of the single $S$. cerevisiae DV10, single L. plantarum and mixed fermentation mango pulp significantly increased from $10.43 \%$ to $12.72 \%, 15.29 \%$ and $16.11 \%$, respectively (Table 1 ). Some scholars have also obtained similar results after fermenting cultures with LAB or S. cerevisiae [16,17]. Other reports have found that the increase in ABTS free radical scavenging was because of an increase in TPC [18]. After $24 \mathrm{~h}$ of fermentation, the mango pulp fermented with the co-cultivation of S. cerevisiae DV10 and L. plantarum showed the strongest ABTS radical scavenging ability.

As shown in Table 1, the ferric-reducing antioxidant power (FRAP) of mango pulp fermented with single S. cerevisiae DV10 slightly increased from $1.11 \mathrm{mM} \mathrm{FeSO}_{4}$ to $1.16 \mathrm{mM} \mathrm{FeSO}_{4}$ over $24 \mathrm{~h}$. The FRAP of the single L. plantarum and mixed fermentation mango pulp significantly $(p<0.05)$ increased to 1.47 and $1.49 \mathrm{mM} \mathrm{FeSO}$, respectively. A previous study has found that FRAP was increased after fermentation with L. plantarum compared to unfermented samples [16]. Some scholars believed that FRAP may be related to the TPC, and the presence of phenolic compounds in a sample extract leads to a reduction in the TPTZ- $\mathrm{Fe}^{3+}$ complex to the TPTZ- $\mathrm{Fe}^{2+}$ form [19]. Therefore, the higher TPC in the assays containing L. plantarum may help to increase FRAP. After $24 \mathrm{~h}$ of fermentation, co-cultivation of L. plantarum and S. cerevisiae DV10 showed the highest FRAP. 


\subsection{Inhibition of LDL Oxidation}

The effect of unfermented and different fermented mango pulp on copper-induced LDL oxidation kinetics is shown in Figure 2. Lipid peroxidation may cause inflammation, cancer, xenobiotic toxicity and peroxidative tissue damage during aging [20]. The high level of oxidized LDL cholesterol is a risk factor for atherosclerosis [21]. The lag time was $50 \mathrm{~min}$ for the unfermented mango pulp, and the lag times of the single S. cerevisiae DV10, single L. plantarum and mixed fermentation mango pulp were 80, 150 and $190 \mathrm{~min}$, respectively. Previous studies have found that some LAB or yeast can inhibit LDL oxidation [22,23]. Therefore, fermentation of mango pulp with L. plantarum and S. cerevisiae DV10 can increase its antioxidant activities. Similarly, it can be seen that the co-cultivation of S. cerevisiae DV10 and L. plantarum had the longest lag time and the strongest LDL oxidation inhibition.

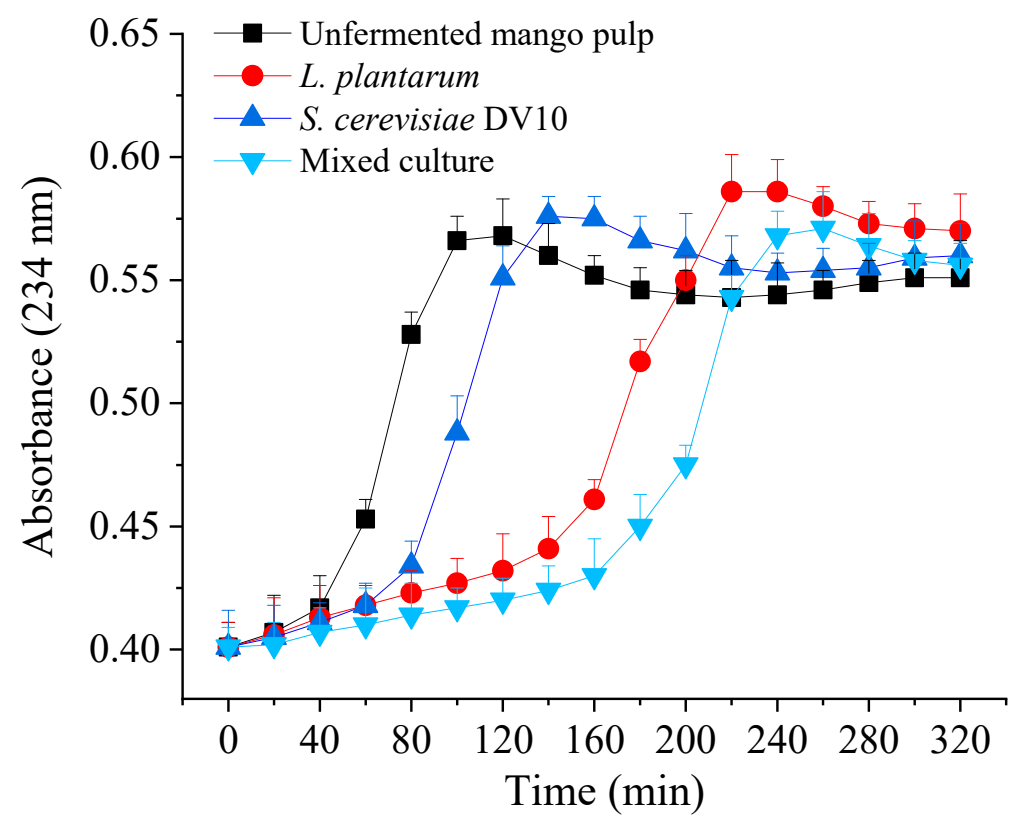

Figure 2. Effect of unfermented mango pulp and fermented mango pulp upon lag time of conjugated diene $(C D)$ formation.

\subsection{Changes in Organic Acids}

The changes in malic, lactic, acetic, citric, oxalic and tartaric acids during $24 \mathrm{~h}$ fermentation of mango pulp were determined (Figure 3). Organic acids were present in the fermentation product because of hydrolysis and microbial activity. Lactic acid was the main metabolite produced in mango slurry fermentation with L. plantarum. As the LAB population increased, the lactic acid content increased. The lactic acid concentrations of single L. plantarum and co-cultured mango pulp were $6.96 \mathrm{~g} / \mathrm{L}$ and $6.12 \mathrm{~g} / \mathrm{L}$ at $24 \mathrm{~h}$ of fermentation, respectively. The malic acid content in unfermented mango slurry was $1.12 \mathrm{~g} / \mathrm{L}$, and it rapidly reduced in the first $8 \mathrm{~h}$ of the fermentation in the assay containing L. plantarum (single and co-culture) to $0.4 \mathrm{~g} / \mathrm{L}$. In the assay containing single $S$. cerevisiae DV10, the malic acid content slowly increased to $1.47 \mathrm{~g} / \mathrm{L}$ during $24 \mathrm{~h}$ fermentation. High malic acid concentrations can have a negative effect on organoleptic properties of beverages [24]. The acetic acid concentrations of the single L. plantarum and co-cultured mango pulp decreased from 8.15 to $2.1 \mathrm{mg} / 100 \mathrm{~mL}$ and $3.04 \mathrm{mg} / 100 \mathrm{~mL}$ over $24 \mathrm{~h}$, respectively. This may be due to consumption of acetic acid as a carbon source by L. plantarum. The decrease of acetic acid may be a positive factor, since this acid may provide an off-flavor in high concentrations [25]. 
a

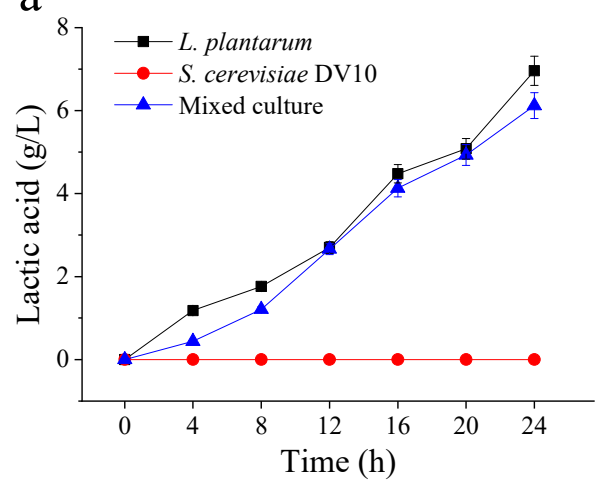

c

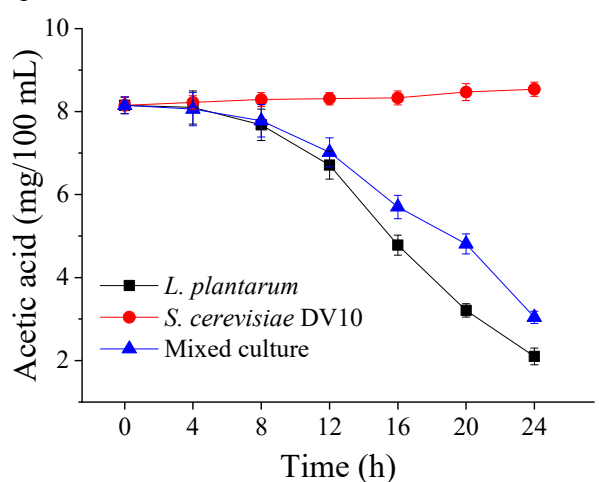

e

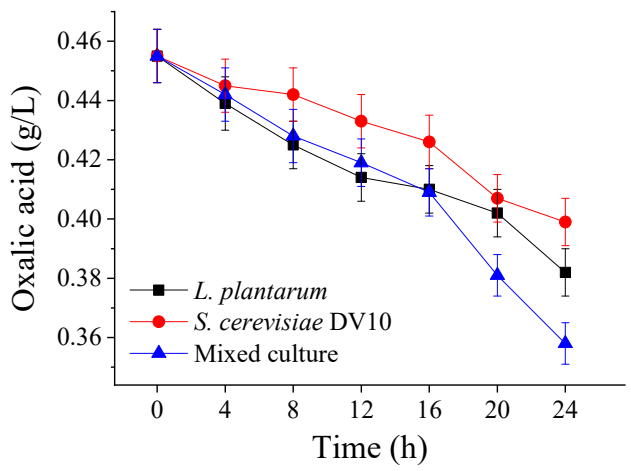

b

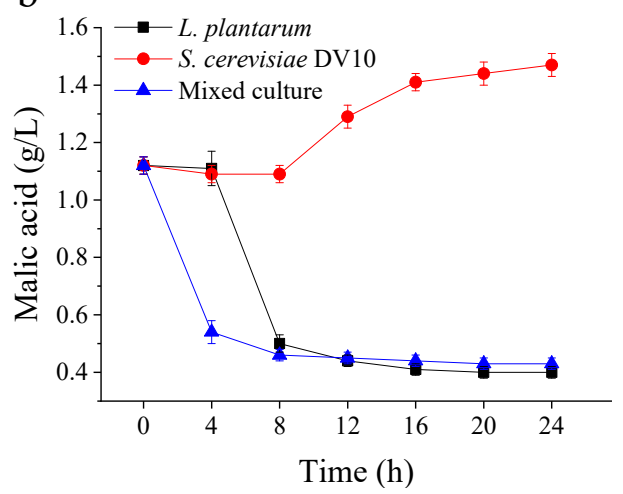

d

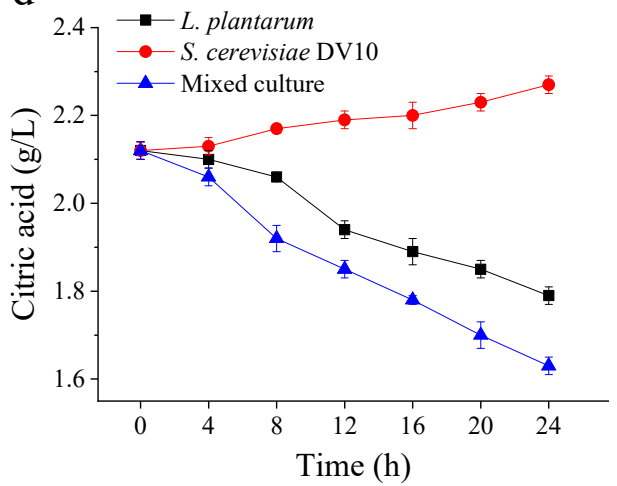

f

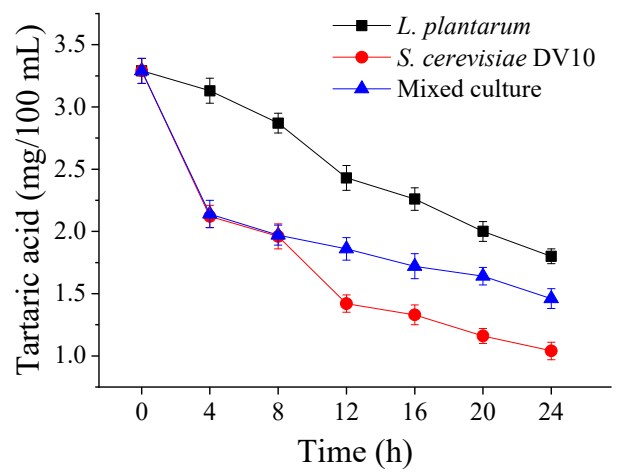

Figure 3. Organic acids evaluated during $24 \mathrm{~h}$ of mango slurry fermentation. (a) Lactic acid; (b) malic acid; (c) acetic acid; (d) citric acid; (e) oxalic acid and (f) tartaric acid.

In the assays containing L. plantarum (single and co-culture), the citric acid content of showed a decreasing trend. The citric acid content of the fermented mango pulp containing L. plantarum decreased from 2.12 to $1.79 \mathrm{~g} / \mathrm{L}$ (single) and $1.63 \mathrm{~g} / \mathrm{L}$ (co-culture) over $24 \mathrm{~h}$. Citric acid can be metabolized by LAB to produce acetic, lactic acids and diacetyl. This metabolism has also been described in other studies of LAB and yeast co-cultivation [26]. After $24 \mathrm{~h}$ of fermentation, the oxalic and tartaric acid concentrations in the fermented mango pulp decreased. The decrease in tartaric acid concentration may have been related to tartrate precipitate formation. These organic acids may interact with other substances such as alcohols and aldehydes, producing other flavor compositions during the fermentation process [27].

\subsection{Changes in Volatile Compounds}

Volatile compounds were detected by using GC-MS for all fermentation assays after $24 \mathrm{~h}$, as shown in Table 2. Terpenes were the main volatile substances in fresh mango pulp. In addition, some esters, acids, ketones and aldehydes were also important in the flavor of fresh mango pulp. Most of the volatiles found in mango pulp have been reported elsewhere [28]. Terpenes have a pungent aroma. 
The terpene content in the fermentation of S. cerevisiae DV10 (single and co-culture) significantly decreased over $24 \mathrm{~h}$. This result was consistent with other reports [29].

S. cerevisiae DV10 (single and co-culture) produced more alcohol compounds than the assay with single L. plantarum. Yeast is an important alcohol producer with unique flavor characteristics that are additionally contributed to by the derived esters [30]. Yeast can produce a variety of volatile compositions, such as esters, alcohols, ketones and aldehydes, which have a positive impact on flavor and organoleptic properties of fermented foods. After $24 \mathrm{~h}$ of fermentation, there were some alcoholic substances with pleasant flavor characteristics. Phenylethyl alcohol emits a rose aroma; 3-methyl-1-butanol has a banana-like and pear-like aroma and 1-hexanol has a rich fruity and aromatic flavor [30]. In the present study, the 3-methyl-1-butanol content was highest in mango slurry inoculated with a single S. cerevisiae DV10. In another study it has fermented cassava with a combination of LAB and yeast and found higher 3-methyl-1-butanol concentrations in a single S. cerevisiae fermentation culture, consistent with our findings [31]. Phenylethanol was detected during all fermentation tests. The phenylethyl alcohol content of the S. cerevisiae DV10 (single and co-culture) fermentation was significantly higher than that of single L. plantarum culture. After $24 \mathrm{~h}$ of fermentation, S. cerevisiae DV10 (single and co-culture) produced more esters, such as ethyl acetate, ethyl octanoate, ethyl quinate and ethyl hexanoate, compared to the assay with single L. plantarum. These esters positively contribute to the overall quality of the fermented mango pulp and most produce moderate "floral" or "fruit" flavors [29].

The aldehydes content in the three cultures decreased over 24 h. S. cerevisiae DV10 (single and co-culture) fermented mango pulp showed a decreased ketone content and an increased alkane content. Compared to unfermented mango pulp, the content of butyric acid in single L. plantarum cultures slightly increased; in the S. cerevisiae DV10 (single and co-culture) cultures, the butyric acid content significantly $(p<0.05)$ decreased. Butyric acid has an unpleasant rancid butter odor and a spicy taste [31], therefore lower levels are desirable.

After $24 \mathrm{~h}$ of fermentation, partial least squares-discriminant analysis (PLS-DA) was performed to correlate volatile compounds with different fermentation measurements. Figure 4 showed the score plot of the volatile compounds, which contributed $97.1 \%$ of the total variance (PLS [1] + PLS [2]). The assay with S. cerevisiae DV10 (single and co-culture) were localized on negative semiaxis of PLS [1] owing to their high hexanoic acid, ethyl ester, acetic acid, 2-phenylethyl ester, phenylethyl alcohol, 3-methyl-1-butanol, isoamyl acetate, octanoic acid, ethyl ester and ethanol contents. The unfermented mango pulp and that fermented with a single L. plantarum were localized on positive semiaxis of PLS [1] mainly owing to their high phellandrene, D-limonene, 3-carene, butanoic acid, (+)-4-carene and 3-penten-2-one contents. Since the fermentation product of single L. plantarum contains more acetic acid, the unfermented mango pulp has a higher hexanoic acid content and can be differentiated from the other fermentation products by PLS [2]. These results showed that unfermented mango pulp and that fermented with a single L. plantarum had an unpleasant pungent odor. The assay with S. cerevisiae DV10 (single and co-culture) had a pleasant fruity and aromatic flavor. 
Table 2. Major volatile compounds (peak area $\times 10^{6}$ ) in mango slurry before and after $24 \mathrm{~h}$ fermentation.

\begin{tabular}{|c|c|c|c|c|c|c|}
\hline Volatile Compounds & RT & RI & Unfermented Mango Slurry & L. plantarum & S. cerevisiae DV10 & Co-Culture \\
\hline \multicolumn{7}{|l|}{ Terpenes } \\
\hline (+)-4-Carene & 10.228 & 919 & $517.02 \pm 25.85 a$ & $535.5 \pm 26.78 \mathrm{a}$ & $263.9 \pm 18.2 b$ & $275.62 \pm 18.78 b$ \\
\hline 3-Carene & 7.312 & 948 & $33.94 \pm 1.7 \mathrm{~b}$ & $37.67 \pm 1.88 \mathrm{a}$ & $16.26 \pm 0.81 \mathrm{~d}$ & $19.59 \pm 0.98 c$ \\
\hline D-Limonene & 8.434 & 1018 & $13.03 \pm 0.65 a$ & $13.53 \pm 0.68 \mathrm{a}$ & $7.07 \pm 0.35 b$ & $6.67 \pm 0.33 b$ \\
\hline$\gamma$-Terpinene & 9.452 & 998 & $2.83 \pm 0.14 a$ & $2.83 \pm 0.14 \mathrm{a}$ & $1.62 \pm 0.08 c$ & $2.32 \pm 0.12 b$ \\
\hline o-Cymene & 9.888 & 1042 & $5.84 \pm 0.29 \mathrm{a}$ & $5.76 \pm 0.29 a$ & $2.93 \pm 0.15 c$ & $4.04 \pm 0.2 \mathrm{~b}$ \\
\hline$\beta$-Myrcene & 7.796 & 958 & $8.28 \pm 0.41 \mathrm{a}$ & $12.93 \pm 0.65 b$ & $5.25 \pm 0.26 c$ & $5.15 \pm 0.26 c$ \\
\hline Phellandrene & 7.685 & 969 & $16.06 \pm 0.8 \mathrm{a}$ & $15.15 \pm 0.76 a$ & $6.67 \pm 0.33 c$ & $8.79 \pm 0.44 b$ \\
\hline$\beta$-Ocimene & 9.65 & 976 & $3.33 \pm 0.17 \mathrm{~b}$ & $4.04 \pm 0.2 \mathrm{a}$ & - & $1.62 \pm 0.08 c$ \\
\hline Caryophyllene & 15.637 & 1494 & $1.21 \pm 0.06 \mathrm{a}$ & - & - & - \\
\hline$\alpha$-Pinene & 4.411 & 948 & $1.82 \pm 0.09 \mathrm{a}$ & $1.92 \pm 0.1 \mathrm{a}$ & - & - \\
\hline$\alpha$-Copaene & 14.05 & 1221 & $1.11 \pm 0.06 a$ & - & - & $0.61 \pm 0.03 b$ \\
\hline Subtotal & & & 604.47 & 629.33 & 303.7 & 324.41 \\
\hline \multicolumn{7}{|l|}{ Alcohols } \\
\hline Ethanol & 2.829 & 463 & - & $22.56 \pm 1.13 c$ & $248.22 \pm 12.41 a$ & $141.84 \pm 7.09 \mathrm{~b}$ \\
\hline 2-Penten-1-ol & 10.871 & 769 & $9.22 \pm 0.46 a$ & $1.65 \pm 0.08 b$ & - & $0.4 \pm 0.02 c$ \\
\hline 1-Hexanol & 11.52 & 860 & $0.54 \pm 0.03 c$ & $1.35 \pm 0.07 \mathrm{a}$ & - & $0.64 \pm 0.03 b$ \\
\hline (Z)-3-Hexen-1-ol & 12.062 & 868 & - & $1.58 \pm 0.08 \mathrm{a}$ & - & $0.3 \pm 0.02 b$ \\
\hline 1-Octanol & 14.979 & 1059 & $0.64 \pm 0.03 \mathrm{~b}$ & $1.68 \pm 0.08 \mathrm{a}$ & - & $1.78 \pm 0.09 a$ \\
\hline (E,Z)-3,6-Nonadien-1-ol & 17.564 & 1175 & $1.68 \pm 0.08 \mathrm{a}$ & $1.82 \pm 0.09 a$ & $0.57 \pm 0.03 c$ & $1.01 \pm 0.05 b$ \\
\hline 3-methyl-1-Butanol & 8.72 & 697 & - & - & $89.18 \pm 4.46 a$ & $52.18 \pm 2.61 b$ \\
\hline Phenylethyl Alcohol & 19.359 & 1136 & - & $1.92 \pm 0.1 \mathrm{c}$ & $53.6 \pm 2.68 a$ & $29.36 \pm 1.47 \mathrm{~b}$ \\
\hline 2-methyl-1-Propanol & 6.289 & 597 & - & - & $14.85 \pm 0.74 a$ & $6.13 \pm 0.31 b$ \\
\hline cis-p-Mentha-2,8-dien-1-ol & 18.55 & 1140 & - & $7.37 \pm 0.37 \mathrm{a}$ & $1.65 \pm 0.08 c$ & $4.38 \pm 0.22 b$ \\
\hline$\left[R-\left(R^{*}, R^{*}\right)\right]-2,3-B u t a n e d i o l$ & 14.564 & 743 & - & - & $4.41 \pm 0.22 \mathrm{a}$ & $1.14 \pm 0.06 \mathrm{~b}$ \\
\hline 3,7-dimethyl-1,6-Octadien-3-ol & 14.835 & 1082 & $0.77 \pm 0.04 \mathrm{~b}$ & $1.11 \pm 0.06 \mathrm{a}$ & $0.57 \pm 0.03 \mathrm{~d}$ & $0.67 \pm 0.03 c$ \\
\hline$\alpha$-Terpineol & 16.889 & 1143 & $0.54 \pm 0.03 a$ & $0.57 \pm 0.03 \mathrm{a}$ & - & - \\
\hline Benzyl alcohol & 18.957 & 1036 & - & $1.38 \pm 0.07 \mathrm{a}$ & - & $0.84 \pm 0.04 b$ \\
\hline 2,4-bis(1,1-dimethylethyl)-Phenol & 23.362 & 1555 & $4.48 \pm 0.22 \mathrm{a}$ & $1.52 \pm 0.08 c$ & $2.93 \pm 0.15 b$ & $1.11 \pm 0.06 \mathrm{~d}$ \\
\hline 6-Nonen-1-ol & 17.155 & 1167 & - & - & $2.26 \pm 0.11 \mathrm{a}$ & $2.42 \pm 0.12 \mathrm{a}$ \\
\hline Eugenol & 21.995 & 1392 & - & $1.18 \pm 0.06 \mathrm{~b}$ & - & $0.84 \pm 0.04 c$ \\
\hline Subtotal & & & 17.88 & 45.69 & 418.24 & 245.06 \\
\hline
\end{tabular}


Table 2. Cont.

\begin{tabular}{|c|c|c|c|c|c|c|}
\hline Volatile Compounds & RT & RI & Unfermented Mango Slurry & L. plantarum & S. cerevisiae DV10 & Co-Culture \\
\hline \multicolumn{7}{|l|}{ Esters } \\
\hline Ethyl Acetate & 2.35 & 586 & $33.03 \pm 1.65 a$ & $5.76 \pm 0.29 d$ & $22.12 \pm 1.11 b$ & $9.49 \pm 0.47 c$ \\
\hline Octanoic acid, ethyl ester & 13.079 & 1183 & $5.05 \pm 0.25 \mathrm{~d}$ & $37.64 \pm 1.88 c$ & $317.14 \pm 15.86 a$ & $193.22 \pm 9.66 b$ \\
\hline Butanoic acid, ethyl ester & 4.816 & 785 & $7.17 \pm 0.36 b$ & $7.17 \pm 0.36 b$ & $8.59 \pm 0.43 a$ & $4.14 \pm 0.21 c$ \\
\hline Decanoic acid, ethyl ester & 16.239 & 1381 & $2.22 \pm 0.11 d$ & $13.54 \pm 0.68 c$ & $116.55 \pm 5.83 a$ & $77.17 \pm 3.86 b$ \\
\hline Hexanoic acid, ethyl ester & 9.265 & 984 & - & - & $77.87 \pm 3.89 a$ & $43.43 \pm 2.17 b$ \\
\hline Dodecanoic acid, ethyl ester & 18.801 & 1580 & $1.72 \pm 0.09 \mathrm{c}$ & - & $15.35 \pm 0.77 a$ & $4.04 \pm 0.2 b$ \\
\hline Isoamyl acetate & 6.779 & 820 & - & - & $28.58 \pm 1.43 a$ & $16.36 \pm 0.82 b$ \\
\hline $\begin{array}{c}\text { Acetic acid,2-phenylethyl } \\
\text { ester }\end{array}$ & 18.348 & 1259 & - & - & $27.98 \pm 1.4 \mathrm{a}$ & $9.8 \pm 0.49 b$ \\
\hline Octanoic acid, methyl ester & 12.267 & 1083 & - & - & $5.86 \pm 0.29 a$ & $5.96 \pm 0.3 a$ \\
\hline Ethyl 9-decenoate & 16.913 & 1371 & - & - & $20.81 \pm 1.04 a$ & - \\
\hline $\begin{array}{l}\text { Tetradecanoic acid, ethyl } \\
\text { ester }\end{array}$ & 21.017 & 1779 & - & - & $4.55 \pm 0.23 a$ & $0.61 \pm 0.03 b$ \\
\hline Decanoic acid, methyl ester & 15.618 & 1282 & - & - & $5.45 \pm 0.27 \mathrm{a}$ & $2.93 \pm 0.15 b$ \\
\hline Hexanoic acid, methyl ester & 8.229 & 884 & - & $1.21 \pm 0.06 b$ & $1.82 \pm 0.06 \mathrm{a}$ & $1.82 \pm 0.09 \mathrm{a}$ \\
\hline 4-Terpinenyl acetate & 6.901 & 1327 & - & - & - & $2.83 \pm 0.14 a$ \\
\hline Formic acid, butyl ester & 7.261 & 783 & $1.62 \pm 0.08 b$ & $2.02 \pm 0.11 \mathrm{a}$ & - & - \\
\hline (S)-1-Alanine ethylamide & 1.283 & 864 & - & $2.53 \pm 0.12 b$ & - & $2.83 \pm 0.15 a$ \\
\hline Formic acid, heptyl ester & 13.33 & 1081 & - & $2.42 \pm 0.12 \mathrm{a}$ & - & - \\
\hline Subtotal & & & 50.81 & 72.29 & 652.67 & 374.63 \\
\hline \multicolumn{7}{|l|}{ Acids } \\
\hline Butanoic acid & 15.839 & 775 & $34.64 \pm 1.53 b$ & $37.02 \pm 1.85 \mathrm{a}$ & $14.04 \pm 0.7 \mathrm{~d}$ & $16.82 \pm 0.84 c$ \\
\hline Hexanoic acid & 23.507 & 974 & $64.99 \pm 3.25 a$ & $22.67 \pm 1.13 b$ & $13.58 \pm 0.68 \mathrm{~d}$ & $16.51 \pm 0.83 c$ \\
\hline Acetic acid & 13.037 & 576 & - & $55.2 \pm 2.76 a$ & - & $17.07 \pm 0.85 b$ \\
\hline Octanoic acid & 20.917 & 1173 & $2.88 \pm 0.14 \mathrm{~d}$ & $4.34 \pm 0.22 c$ & $20.91 \pm 1.05 a$ & $15.91 \pm 0.8 b$ \\
\hline n-Decanoic acid & 22.978 & 1372 & $0.91 \pm 0.05 c$ & $0.4 \pm 0.02 \mathrm{~d}$ & $13.79 \pm 0.69 a$ & $4.75 \pm 0.24 b$ \\
\hline Octadecanoic acid & 24.14 & 2167 & $3.23 \pm 0.16 c$ & $17.57 \pm 0.88 b$ & $27.72 \pm 1.39 a$ & $1.46 \pm 0.07 \mathrm{~d}$ \\
\hline Dodecanoic acid & 24.845 & 1570 & $1.31 \pm 0.07 \mathrm{~d}$ & $3.43 \pm 0.17 a$ & $1.72 \pm 0.09 c$ & $3.08 \pm 0.15 b$ \\
\hline n-Hexadecanoic acid & 24.718 & 1968 & - & $9.04 \pm 0.45 a$ & - & $2.53 \pm 0.13 b$ \\
\hline Subtotal & & & 107.96 & 149.67 & 91.76 & 78.13 \\
\hline
\end{tabular}


Table 2. Cont.

\begin{tabular}{|c|c|c|c|c|c|c|}
\hline Volatile Compounds & RT & RI & Unfermented Mango Slurry & L.plantarum & S. cerevisiae DV10 & Co-Culture \\
\hline \multicolumn{7}{|l|}{ Aldehydes } \\
\hline (E,Z)-2,6-Nonadienal & 15.366 & 1120 & $9.29 \pm 0.46 a$ & - & - & - \\
\hline Furfural & 13.331 & 831 & $3.74 \pm 0.19 a$ & - & - & - \\
\hline (E,E)-2,4-Heptadienal & 13.865 & 921 & $4.24 \pm 0.21 \mathrm{a}$ & - & - & - \\
\hline Nonanal & 12.286 & 1104 & $3.74 \pm 0.19 a$ & - & - & - \\
\hline Citral & 16.762 & 1174 & $7.78 \pm 0.39 \mathrm{~b}$ & $10.5 \pm 0.53 a$ & - & $11.51 \pm 0.58 \mathrm{a}$ \\
\hline 2-Hexenal & 8.754 & 814 & $2.63 \pm 0.13 a$ & - & - & - \\
\hline Subtotal & & & 31.42 & 10.5 & 0 & 11.51 \\
\hline \multicolumn{7}{|l|}{ Ketones } \\
\hline 3-Penten-2-one & 6.686 & 662 & $17.17 \pm 0.86 b$ & $28.89 \pm 1.44 \mathrm{a}$ & - & - \\
\hline 4-hydroxy-2-Pentanone & 13.22 & 817 & $10.2 \pm 0.51 \mathrm{a}$ & $9.7 \pm 0.48 a$ & $3.13 \pm 0.16 \mathrm{~b}$ & $3.03 \pm 0.15 b$ \\
\hline 5-ethyldihydro-2(3H)-Furanone & 16.831 & 986 & $10.4 \pm 0.52 a$ & $7.68 \pm 0.38 b$ & $2.83 \pm 0.14 \mathrm{~d}$ & $4.75 \pm 0.24 c$ \\
\hline 5-butyldihydro-2(3H)-Furanone & 19.425 & 1184 & $3.54 \pm 0.18 \mathrm{a}$ & $1.62 \pm 0.08 b$ & - & - \\
\hline trans- $\beta$-Ionone & 19.765 & 1457 & $3.03 \pm 0.15 a$ & $1.01 \pm 0.05 \mathrm{~d}$ & $2.32 \pm 0.12 b$ & $1.82 \pm 0.09 \mathrm{c}$ \\
\hline 2-Heptanone & 8.068 & 853 & - & $4.55 \pm 0.23 a$ & - & $1.01 \pm 0.05 b$ \\
\hline Acetoin & 10.085 & 717 & - & $19.38 \pm 0.97 a$ & $9.59 \pm 0.48 c$ & $16.16 \pm 0.81 b$ \\
\hline 2,3-Butanedione & 3.523 & 691 & - & $6.16 \pm 0.31 a$ & - & - \\
\hline 1-(3-methylphenyl)-Ethanone & 17.797 & 1142 & $5.56 \pm 0.28 \mathrm{a}$ & - & - & - \\
\hline 4-methyl-4-Hexen-3-one & 6.761 & 838 & $4.55 \pm 0.23 \mathrm{a}$ & - & - & - \\
\hline tetrahydro-6-methyl-2H-Pyran-2-one & 17.936 & 1006 & $13.94 \pm 0.7 \mathrm{c}$ & $8.32 \pm 0.42 \mathrm{~d}$ & $16.78 \pm 0.64 a$ & $15.08 \pm 0.75 b$ \\
\hline Subtotal & & & 68.39 & 87.31 & 34.65 & 41.85 \\
\hline \multicolumn{7}{|l|}{ Alkanes } \\
\hline (2-methyl-1-propenyl)-Benzene & 12.993 & 1077 & $14.04 \pm 0.7 \mathrm{a}$ & $12.63 \pm 0.63 \mathrm{ab}$ & $11.92 \pm 0.6 b$ & $10.2 \pm 0.51 \mathrm{c}$ \\
\hline 1,3,8-p-Menthatriene & 12.243 & 1029 & - & $2.32 \pm 0.12 \mathrm{a}$ & - & - \\
\hline bis(1-methylethylidene)-Cyclobutene & 12.81 & 983 & $2.63 \pm 0.13 a$ & $2.02 \pm 0.1 \mathrm{~b}$ & $1.52 \pm 0.08 c$ & $1.01 \pm 0.05 \mathrm{~d}$ \\
\hline Styrene & 9.588 & 883 & - & - & $11.41 \pm 0.57 \mathrm{a}$ & $2.12 \pm 0.11 b$ \\
\hline 2,6,10,14-tetramethyl-Pentadecane & 20.42 & 1653 & - & - & $11.51 \pm 0.58 \mathrm{a}$ & $7.07 \pm 0.35 b$ \\
\hline Heneicosane & 18.106 & 2109 & $12.83 \pm 0.64 b$ & $10.91 \pm 0.55 c$ & $20.5 \pm 1.03 a$ & $18.28 \pm 0.91 a$ \\
\hline 2-methyloctacosane & 18.397 & 2840 & $2.32 \pm 0.12 a$ & - & - & - \\
\hline Subtotal & & & 31.82 & 27.88 & 56.86 & 38.68 \\
\hline \multicolumn{7}{|l|}{ Others } \\
\hline trans-2-(2-Pentenyl)furan & 10.603 & 1048 & $1.82 \pm 0.09 \mathrm{~b}$ & $2.43 \pm 0.09 a$ & - & $0.91 \pm 0.05 c$ \\
\hline 1,1-diethoxy-Ethane & 2.439 & 705 & - & - & $13.23 \pm 0.66 a$ & $6.77 \pm 0.34 \mathrm{~b}$ \\
\hline 2,3-dihydro-Benzofuran & 23.969 & 1036 & - & $3.74 \pm 0.19 a$ & $0.81 \pm 0.03 b$ & $0.81 \pm 0.04 \mathrm{~b}$ \\
\hline 2,4,5-trimethyl-1,3-Dioxolane & 3.022 & 761 & - & - & $12.02 \pm 0.47 \mathrm{~b}$ & $13.53 \pm 0.38 a$ \\
\hline Subtotal & & & 1.82 & 6.17 & 26.06 & 22.02 \\
\hline
\end{tabular}

Values are expressed as the mean \pm SD. Values with different letters (a-d) in the same row are significantly different at $p<0.05$. RT, retention time; RI, retention index; PA, peak area; “-“, not detected. 
a

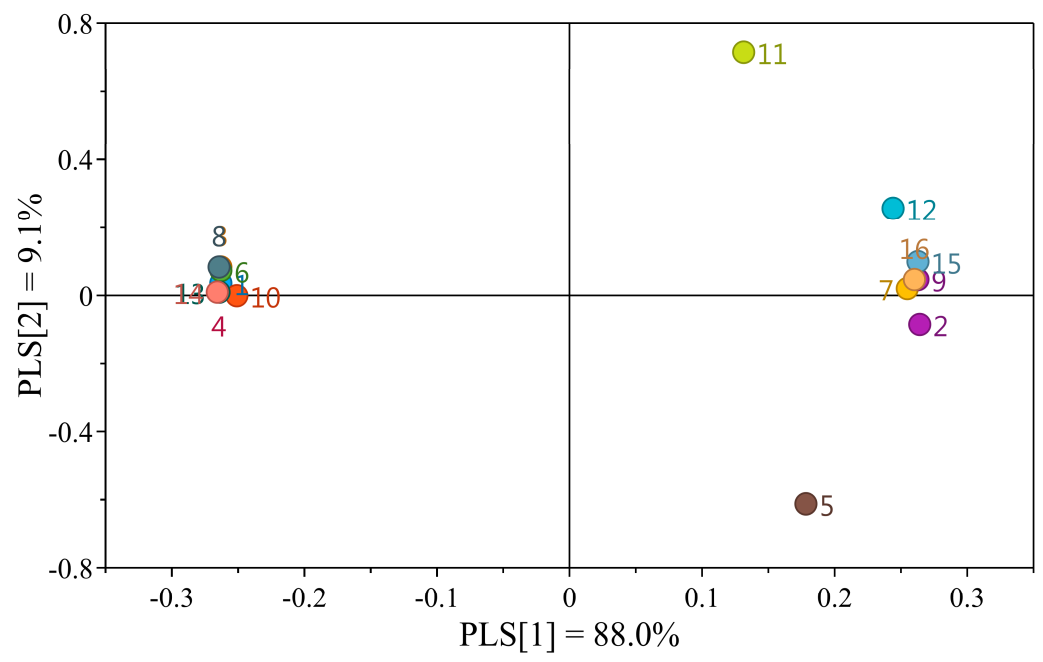

$\mathrm{b}$

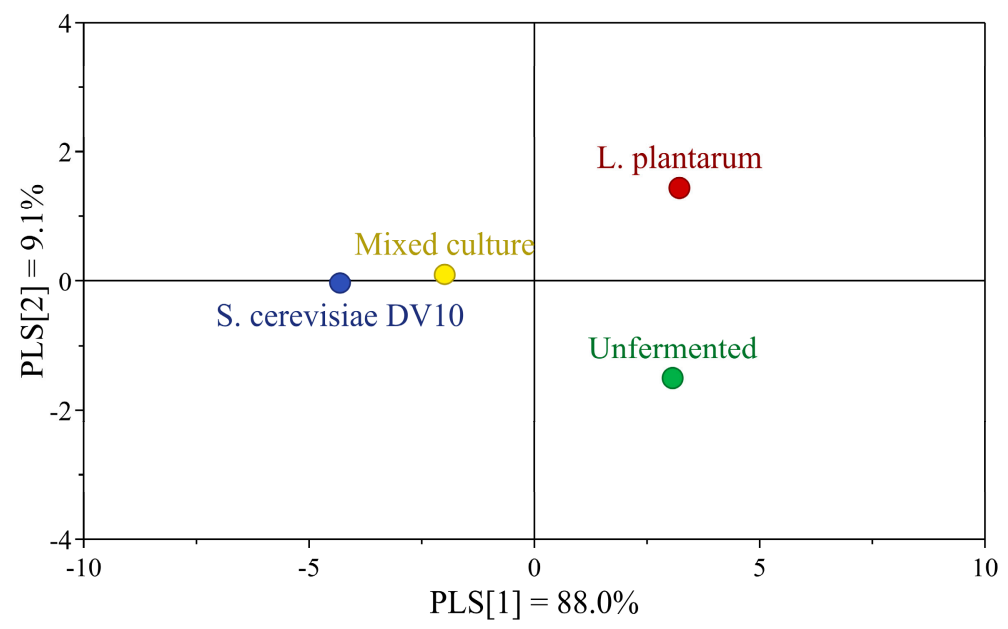

Intercepts: $\mathrm{R}^{2} \mathrm{Y}=0.339, \mathrm{Q}^{2} \mathrm{Y}=-0.029$

Figure 4. (a) Loadings scatter plot of PLS-DA of different constituents. 1, Phenylethyl Alcohol; 2, Phellandrene; 3, Octanoic acid, ethyl ester; 4, Hexanoic acid, ethyl ester; 5, Hexanoic acid; 6, Ethanol; 7, o-Limonene; 8, Decanoic acid, ethyl ester; 9, Butanoic acid; 10, Acetic acid, 2-phenylethyl ester; 11. Acetic acid; 12, 3-Penten-2-one; 13, Isoamyl acetate; 14, 3-methyl-1-Butanol; 15, 3-Carene; 16, (+)-4-Carene. (b) Scores scatter plot in different probiotics fermentation of mango slurry.

\section{Materials and Methods}

\subsection{Materials}

Tainong mangoes were obtained from Hainan Dachuan Food Co., Ltd. (Hainan, China). L. plantarum GIM1.140 was obtained from Guangdong Microbial Culture Center (Guangdong, China). The active dry yeast strain (S. cerevisiae DV10) was obtained from Lallemand Inc. (Montreal, Canada).

\subsection{Fermented Mango Slurry}

Mango peeled and added 10\% water to beat. Its soluble solid content was increased to $21.6^{\circ}$ Brix with sucrose. Next, mango slurry was heated for $10 \mathrm{~min}$ at $90^{\circ} \mathrm{C}$ and cooled to $25^{\circ} \mathrm{C}$. Microbial cells were inoculated in the mango slurry with a population of $5 \log \mathrm{CFU} / \mathrm{mL}$ for S. cerevisiae DV10 
and $7 \log \mathrm{CFU} / \mathrm{mL}$ for L. plantarum in both single and co-culture fermentations. Fermentation was conducted at $28^{\circ} \mathrm{C}$ for $24 \mathrm{~h}$, and the process was repeated three times.

\subsection{Enumeration of Microorganisms}

The total LAB and yeast populations were determined as previously described method [25]. The total LAB populations were determined by plating in the MRS agar (supplemented with $50 \mathrm{mg} / \mathrm{L}$ of nystatin), and plates were incubated at $37^{\circ} \mathrm{C}$ for $48 \mathrm{~h}$. The total yeast populations were determined by plating in YPD agar (supplemented with $50 \mathrm{mg}$ of chlortetracycline and $100 \mathrm{mg}$ of chloramphenicol), and plates were incubated at $30{ }^{\circ} \mathrm{C}$ for $48 \mathrm{~h}$. The colony-forming units (CFU) were enumerated. The analyses were performed in triplicate.

\subsection{The $\mathrm{pH}$, Total Soluble Solids and Reducing Sugar Content}

The $\mathrm{pH}$ value was determined by using a pH meter (FE20 pH meter). The Brix value was determined with a portable refractometer (ATAGO, Tokyo, Japan). The reducing sugar content was determined using the 3,5-dinitrosalicylic acid (DNS) method [32].

\subsection{TPC}

The TPC of the samples were measured in accordance with the Folin-Ciocalteu colorimetric method with several modifications [33]. A $0.3 \mathrm{~mL}$ sample was mixed with $0.2 \mathrm{~mL}$ of the Folin-Ciocalteu reagent and placed for $5 \mathrm{~min}$. Next, $1.3 \mathrm{~mL}$ of $10 \% \mathrm{Na}_{2} \mathrm{CO}_{3}$ solution was added, and the mixture was reacted $1.5 \mathrm{~h}$ in the dark. Samples absorbance at $765 \mathrm{~nm}$ was determined. Using gallic acid as the standard, the TPC of the samples were expressed as milligrams of gallic acid equivalents (GAEs).

\subsection{Scavenging Effect on ABTS Radical}

The sample was measured using the previously described method with minor modifications [34]. The $7.4 \mathrm{mM}$ ABTS solution was added to $2.6 \mathrm{mM}$ potassium persulfate solution, and kept in the dark at room temperature for $12 \mathrm{~h}$. The ABTS radical solution was diluted with $10 \mathrm{mM}$ PBS to an absorbance of $0.70 \pm 0.02$. A total of $3.9 \mathrm{~mL}$ of diluted ABTS radical solution was mixed with $0.1 \mathrm{~mL}$ of sample, and kept in the dark for $6 \mathrm{~min}$. Absorbance at $734 \mathrm{~nm}$ was determined. The ABTS radical scavenging capacity was calculated using the following formula:

$$
\text { Radical scavenging capacity }(\%)=\left[\left(\mathrm{A}_{0}-\mathrm{A}_{1}\right) / \mathrm{A}_{0}\right] \times 100,
$$

where $A_{0}$ is the control (PBS) absorbance, and $A_{1}$ is the extract absorbance.

\subsection{Determination of FRAP}

FRAP assay was measured following the previously described method with some improvements [16]. FRAP solution contained $0.5 \mathrm{~mL}$ of $20 \mathrm{mM} \mathrm{FeCl} \mathrm{F}_{3} \cdot 6 \mathrm{H}_{2} \mathrm{O}, 0.5 \mathrm{~mL}$ of $10 \mathrm{M}$ 2,4,6-tris(2-pyridyl)-s-triazine solution and $5 \mathrm{~mL}$ of $0.3 \mathrm{M}$ acetate buffer. One $\mathrm{mL}$ of sample with $3 \mathrm{~mL}$ of the FRAP solution were mixed well, and stand at dark for $50 \mathrm{~min}$. The absorbance at $593 \mathrm{~nm}$ was determined. Using $\mathrm{FeSO}_{4}$ as standard, and the final results were expressed as $\mathrm{FeSO}_{4}$ equivalents.

\subsection{Copper-Induced LDL Oxidation}

LDL oxidation was determined using a previously described method. The oxidation kinetics were determined by absorbance changes [23]. In this study, a 2-mL LDL was added to the sample $(0.05 \%$ final concentration). The sample was placed at $37^{\circ} \mathrm{C}$, and was incubated with a $\mathrm{CuSO}_{4}$ solution for 15 min to initiate a peroxidation reaction. 


\subsection{Organic Acid Content}

Fermented mango slurry organic acid contents were determined on a high-performance liquid chromatography (HPLC) system equipped with UV-visible detector and a ZORBAX SB-Aq column $(4.6 \mathrm{~mm} \times 250 \mathrm{~mm}, 5 \mu \mathrm{m}$; Agilent, Santa Clara, CA, USA). The column was eluted with the mobile phase (0.02 $\mathrm{M}$ ammonium dihydrogen phosphate: methanol $=97: 3$ ) at a flow rate of $0.8 \mathrm{~mL} / \mathrm{min}$ at $30{ }^{\circ} \mathrm{C}[35]$.

\subsection{Volatile Compound Content}

The volatile compound content of the sample was measured as the previously described method [36], with minor modifications. Samples were collected for headspace extraction using an solid phase microextraction autosampler (Supelco, USA) for $30 \mathrm{~min}$. Thermal desorption occurred in the injector port for $3 \mathrm{~min}$ at $230^{\circ} \mathrm{C}$. Separation was carried out on a Ptx-Wax capillary column of $30 \mathrm{~m} \times 0.25 \mathrm{~mm}$. The carrier gas He at $1 \mathrm{~mL} / \mathrm{min}$, and the temperature was set at $40^{\circ} \mathrm{C}$ for $2 \mathrm{~min}$, ramp of $5{ }^{\circ} \mathrm{C} / \mathrm{min}$ up to $160{ }^{\circ} \mathrm{C}$, and finally to $230^{\circ} \mathrm{C}$ at $10^{\circ} \mathrm{C} / \mathrm{min}$. Using the $\mathrm{GC} / \mathrm{MS}$ solution software to collect data. The eluted volatile compositions were matched with the NIST 115 libraries via mass spectrometry and confirmed by linear retention index values.

\subsection{Statistical Analysis}

All the experiments were conducted in triplicate and data were reported as mean \pm SD. Analysis of variance and significant difference tests were performed to identify differences among means by one-way ANOVA using SPSS software (version 16.0, Chicago, IL, USA).

\section{Conclusions}

This study showed the possibility of using a combination of S. cerevisiae DV10 and L. plantarum as starter cultures during mango slurry fermentation. The co-cultures of S. cerevisiae DV10 and L. plantarum could increase the product's antioxidant activity. In addition, a co-culture with the L. plantarum and S. cerevisiae DV10 could decrease terpenes and produced various volatile compounds (alcohols and esters) that might improve the aromatic profiles of the fermented mango slurry. The sensory properties of the products should be evaluated at the next step. Further studies regarding the viability and benefits of these strains in the gut after consumption also need to be conducted.

Author Contributions: Conceptualization, W.C. (Weijun Chen) and Q.Z.; methodology, W.C. (Wenxue Chen); formal analysis, H.C. and X.J.; writing—original draft preparation, X.J.; writing-review and editing, W.C. (Weijun Chen), Q.Z. and X.J.

Funding: This research was funded by the National Natural Science Foundation of China [No. 31960509].

Conflicts of Interest: The authors declare no conflict of interest.

\section{References}

1. Hill, C.; Guarner, F.; Reid, G.; Gibson, G.R.; Merenstein, D.J.; Pot, B.; Morelli, L.; Canani, R.B.; Flint, H.J.; Salminen, S.; et al. The International Scientific Association for Probiotics and Prebiotics consensus statement on the scope and appropriate use of the term probiotic. Nat. Rev. Gastroenterol. Hepatol. 2014, 11, 506-514. [CrossRef]

2. Kandylis, P.; Pissaridi, K.; Bekatorou, A.; Kanellaki, M.; Koutinas, A.A. Dairy and non-dairy probiotic beverages. Curr. Opin. Food Sci. 2016, 7, 58-63. [CrossRef]

3. Panda, S.K.; Behera, S.K.; Qaku, X.W.; Sekar, S.; Ndinteh, D.T.; Nanjundaswamy, H.M.; Ray, R.C.; Kayitesi, E. Quality enhancement of prickly pears (Opuntia sp.) juice through probiotic fermentation using Lactobacillus fermentum-ATCC 9338. LWT-Food Sci. Technol. 2017, 75, 453-459. [CrossRef]

4. Shori, B.A. Influence of food matrix on the viability of probiotic bacteria: A review based on dairy and non-dairy beverages. Food Biosci. 2016, 13, 1-8. [CrossRef] 
5. Asif, A.; Farooq, U.; Akram, K.; Hayat, Z.; Shafi, A.; Sarfraz, F.; Sidhu, M.A.I.; Rehman, H.; Aftab, S. Therapeutic potentials of bioactive compounds from mango fruit wastes. Trends Food Sci. Technol. 2016, 53, 102-112. [CrossRef]

6. Ntsoanea, M.L.; Zude-Sassea, M.; Mahajana, P.; Sivakumar, D. Quality assesment and postharvest technology of mango: A review of its current status and future perspectives. Sci. Hortic-Amst. 2019, 249, 77-85. [CrossRef]

7. Sivakumar, D.; Jiang, Y.; Yahia, E.M. Maintaining mango (Mangifera indica L.) fruit quality during the export chain. Food Res. Int. 2011, 44, 1254-1263. [CrossRef]

8. Jahurul, M.; Zaidul, I.; Ghafoor, K.; Al-Juhaimi, F.Y.; Nyam, K.; Norulaini, N.; Sahena, F.; Omar, A.M. Mango (Mangifera indica L.) by-products and their valuable components: A review. Food Chem. 2015, 183, 173-180. [CrossRef]

9. Santos, C.C.; Libeck, B.S.; Schwan, R.F. Co-culture fermentation of peanut-soy milk for the development of a novel functional beverage. Int. J. Food Microbiol. 2014, 186, 32-41. [CrossRef]

10. Angelov, A.; Gotcheva, V.; Hristozova, T.; Gargova, S. Application of pure and mixed probiotic lactic acid bacteria and yeast cultures for oat fermentation. J. Sci. Food Agric. 2005, 85, 2134-2141. [CrossRef]

11. Rathore, S.; Salmerón, I.; Pandiella, S.S. Production of potentially probiotic beverages using single and mixed cereal substrates fermented with lactic acid bacteria cultures. Food Microbiol. 2012, 30, 239-244. [CrossRef] [PubMed]

12. Pandey, K.B.; Rizvi, S.I. Plant polyphenols as dietary antioxidants in human health and disease. Oxid. Med. Cell. Longev. 2009, 2, 270-278. [CrossRef] [PubMed]

13. Panda, S.K.; Sahu, U.C.; Behera, S.K.; Ray, R.C. Bio-processing of bael [Aegle marmelos L.] fruits into wine with antioxidants. Food Biosci. 2014, 5, 34-41. [CrossRef]

14. Pérez-Gregorio, M.R.; Regueiro, J.; Alonso-González, E.; Pastrana-Castro, L.M.; Simal-Gándara, J. Influence of alcoholic fermentation process on antioxidant activity and phenolic levels from mulberries (Morus nigra L.). LWT-Food Sci. Technol. 2011, 44, 1793-1801. [CrossRef]

15. Ankolekar, C.; Pinto, M.; Greene, D.; Shetty, K. In vitro bioassay based screening of antihyperglycemia and antihypertensive activities of Lactobacillus acidophilus fermented pear juice. Innov. Food Sci. Emerg. 2012, 13, 221-230. [CrossRef]

16. Xiao, Y.; Wang, L.X.; Rui, X.; Li, W.; Chen, X.H.; Jiang, M.; Dong, M.S. Enhancement of the antioxidant capacity of soy whey by fermentation with Lactobacillus plantarum B1-6. J. Funct. Foods 2015, 12, 33-44. [CrossRef]

17. Li, X.C.; Xing, Y.; Cao, L.; Xu, Q.L.; Li, S.H.; Wang, R.R.; Jiang, Z.J.; Che, Z.M.; Lin, H.B. Effects of six commercial, Saccharomyces cerevisiae, strains on phenolic attributes, antioxidant activity, and aroma of kiwifruit (Actinidia deliciosa cv.) wine. Biomed Res. Int. 2017, 2017, 1-10. [CrossRef]

18. Kim, J.; Choi, J.N.; Kang, D.; Son, G.H.; Kim, Y.; Choi, H.; Kwon, D.Y.; Lee, C.H. Correlation between antioxidative activities and metabolite changes during Cheonggukjang fermentation. Biosci. Biotechnol. Biochem. 2011, 75, 732-739. [CrossRef]

19. Vadivel, V.; Stuetz, W.; Scherbaum, V.; Biesalski, H.K. Total free phenolic content and health relevant functionality of Indian wild legume grains: Effect of indigenous processing methods. J. Food Compos. Anal. 2011, 24, 935-943. [CrossRef]

20. Middleton, E.; Kandaswami, C.; Theoharides, T.C. The effects of plant flavonoids on mammalian cells: Implications for inflammation, heart disease, and cancer. Pharmacol. Rev. 2000, 52, 673-751. [CrossRef]

21. Camargo, A.C.D.; Regitano-d'Arce, M.A.B.; Biasoto, A.C.T.; Shahidi, F. Low molecular weight phenolics of grape juice and winemaking byproducts: Antioxidant activities and inhibition of oxidation of human low-density lipoprotein cholesterol and DNA strand breakage. J. Agric. Food Chem. 2014, 62, 12159-12171. [CrossRef] [PubMed]

22. Lee, D.K.; Jang, S.; Baek, E.H.; Kim, M.J.; Lee, K.S.; Shin, H.S.; Chung, M.J.; Kim, J.E.; Lee, K.O.; Ha, N.J. Lactic acid bacteria affect serum cholesterol levels, harmful fecal enzyme activity, and fecal water content. Lipids Health Dis. 2009, 8, 1-8. [CrossRef] [PubMed]

23. Li, H.; Wang, X.; Li, Y.; Li, P.; Wang, H. Polyphenolic compounds and antioxidant properties of selected China wines. Food Chem. 2009, 112, 454-460. [CrossRef] 
24. Duarte, W.F.; Dias, D.R.; Pereira, G.V.M.; Gervásio, I.M.; Schwan, R.F. Indigenous and inoculated yeast fermentation of gabiroba (Campomanesia pubescens) pulp for fruit wine production. J. Ind. Microbiol. Biotechnol. 2009, 36, 557-569. [CrossRef]

25. Menezes, A.G.T.; Ramos, C.L.; Dias, D.R.; Schwan, R.F. Combination of probiotic yeast and lactic acid bacteria as starter culture to produce maize-based beverages. Food Res. Int. 2018, 111, 187-197. [CrossRef]

26. Álvarez-Martín, P.; Flórez, A.B.; Hernández-Barranco, A.; Mayo, B. Interaction between dairy yeasts and lactic acid bacteria strains during milk fermentation. Food Control 2008, 19, 62-70. [CrossRef]

27. Liu, S.N.; Han, Y.; Zhou, Z.J. Lactic acid bacteria in traditional fermented Chinese foods. Food Res. Int. 2011, 44, 643-651. [CrossRef]

28. Pino, J.A.; Mesa, J.; Muñoz, Y.; Marti, M.P.; Marbot, R. Volatile components from mango (Mangifera indica L.) cultivars. J. Agric. Food Chem. 2005, 53, 2213-2223. [CrossRef]

29. Li, X.; Yu, B.; Curran, P.; Liu, S.Q. Chemical and volatile composition of mango wines fermented with different Saccharomyces cerevisiae yeast strains. S. Afr. J. Enol. Vitic. 2011, 32, 117-128. [CrossRef]

30. Longo, M.A.; Sanromán, M.A. Production of food aroma compounds: Microbial and enzymatic methodologies. Food Technol. Biotechnol. 2006, 44, 335-353. [CrossRef]

31. Freire, A.L.; Ramos, C.L.; Schwan, R.F. Microbiological and chemical parameters during cassava based-substrate fermentation using potential starter cultures of lactic acid bacteria and yeast. Food Res. Int. 2015, 76, 787-795. [CrossRef] [PubMed]

32. Saqib, A.A.N.; Whitney, P.J. Differential behaviour of the dinitrosalicylic acid (DNS) reagent towards monoand di-saccharide sugars. Biomass Bioenergy 2011, 35, 4748-4750. [CrossRef]

33. De Sá, L.Z.C.M.; Castro, P.F.S.; Lino, F.M.A.; Bernardes, M.J.C.; Viegas, J.C.J.; Dinis, T.C.P.; Santana, M.J.; Romao, W.; Vaz, B.G.; Lião, L.M.; et al. Antioxidant potential and vasodilatory activity of fermented beverages of jabuticaba berry (Myrciaria jaboticaba). J. Funct. Foods 2014, 8, 169-179. [CrossRef]

34. Delgado-Andrade, C.; Rufián-Henares, J.A.; Morales, F.J. Assessing the antioxidant activity of melanoidins from coffee brews by different antioxidant methods. J. Agric. Food Chem. 2005, 53, 7832-7836. [CrossRef] [PubMed]

35. Zhao, J.; Li, H.; Xi, W.; An, W.; Niu, L.; Cao, Y.; Wang, C.F.; Wang, Y.J.; Yin, Y. Changes in sugars and organic acids in wolfberry (Lycium barbarum L.) fruit during development and maturation. Food Chem. 2015, 173, 718-724. [CrossRef]

36. Lee, P.R.; Chong, S.M.; Yu, B.; Curran, P.; Liu, S.Q. Effects of sequentially inoculated Williopsis saturnus and Saccharomyces cerevisiae on volatile profiles of papaya wine. Food Res. Int. 2012, 45, 177-183. [CrossRef]

Sample Availability: Samples of the compounds are available from the authors.

(C) 2019 by the authors. Licensee MDPI, Basel, Switzerland. This article is an open access article distributed under the terms and conditions of the Creative Commons Attribution (CC BY) license (http://creativecommons.org/licenses/by/4.0/). 